\title{
El genio secreto del catalejo (Kikkertens Hemmelighedsfulde Aand)
}

\section{Artículo de investigación artística}

\section{Sandra Rengifo}

Pontificia Universidad Javeriana

s.rengifo@javeriana.edu.co

\section{Fernado Escobar Neira}

Universidad Nacional de Colombia, Sede Medellín

fescobarne@unal.edu.co

Recibido: 2 de mayo de 2018

Aprobado: 20 de mayo de 2018

Cómo citar este artículo: Rengifo, Sandra y Escobar Neira, Fernando (2018). El genio secreto del catalejo (Kikkertens Hemmeligjedsfulde Aand). Calle 14: revista de investigación en el campo del arte 13(24), pp. 254287. DOI: https://doi.org/10.14483/21450706.13525

Para el hombre que fue y será mi maestro y mi inspiración: mi padre. Ahora desde el silencio de la eternidad, estará entre nosotros como mi 'Genio secreto del catalejo'. Gracias padre por tu legado que a través de tus lentes, espero me ayuden, para volverte a capturar en el infinito. Silvio César Rengifo (1944 -2018). 


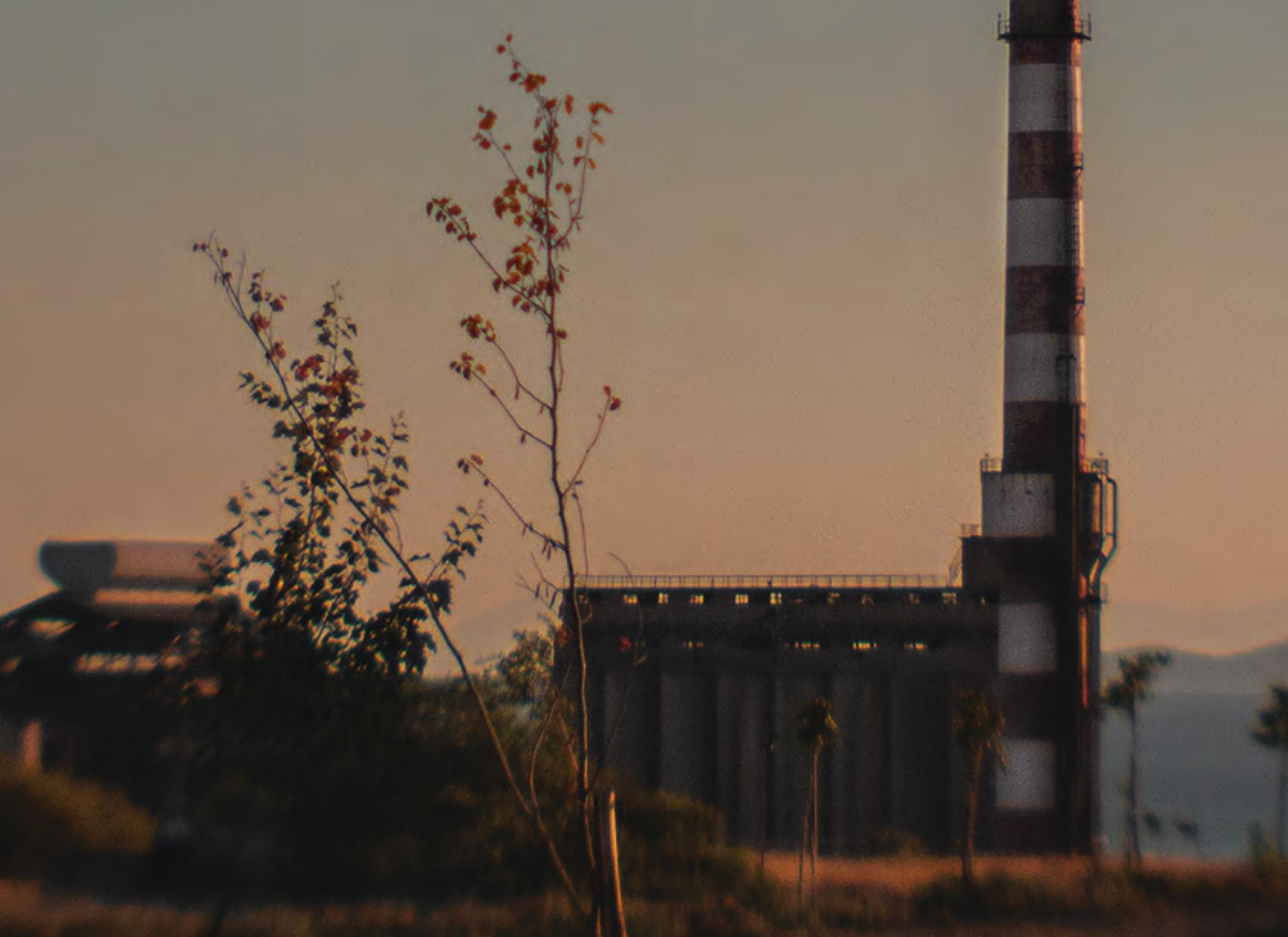




\title{
Resumen
}

Este texto está construido sobre diversos acercamientos conceptuales y teóricos al proyecto El genio secreto del catalejo (Kikkertens Hemmelighedsfulde Aand) de la artista Sandra Rengifo. La perspectiva de análisis puesta en trabajo se aleja de discursos propios de la historia del arte y de la estética, y por el contrario, instala preguntas más cercanas a campos de conocimiento como la geografía cultural, los estudios del paisaje y los estudios visuales. El objetivo principal es describir la relación y tensiones que mantiene el proyecto artístico con respecto a espacialidades, objetos, lugares y paisajes. Con este fin, nociones relativas a la repetición y a la fragmentación propias tanto de los referentes como de las narrativas que implicó el proyecto, fueron útiles para acopiar y reordenar los indicios sugeridos por Rengifo.

\section{Palabras claves}

Paisaje, fragmentación, repetición, Kierkegaard.

\section{The Secret Genius of the Spyglass (Kikkertens Hemmelighedsfulde Aand)}

\begin{abstract}
This text is constructed on diverse conceptual and theoretical approaches to the project The Secret Genius of the Spyglass (Kikkertens Hemmelighedsfulde Aand) of the artist Sandra Rengifo. The perspective of analysis put into work moves away from discourses typical of the history of art and aesthetics, and, on the contrary, puts forward questions closer to fields such as cultural geography, landscape studies and visual studies. The main objective is to describe the relationship and tensions that the artistic project maintains with respect to spatialities, objects, places and landscapes. To this end, notions related to the repetition and fragmentation of both the referents and the narratives that the project involved were useful for collecting and rearranging the indications suggested by Rengifo.

\section{Keywords}

Landscape, fragmentation, repetition, Kierkegaard.

\section{Résumé}

Ce texte est construit sur diverses approches conceptuelles et théoriques au projet Le génie secret de la longue-vue (Kikkertens Hemmelighedsfulde Aand) de l'artiste Sandra Rengifo. La perspective de l'analyse mise en œuvre s'éloigne des discours typiques de l'histoire de l'art et de l'esthétique, et, au contraire, présent des questions plus proches des domaines de la connaissance tels que la géographie culturelle, les études du paysage et les études visuelles. L'objectif principal est de décrire la relation et les tensions que le projet artistique entretient avec les espaces, les objets, les lieux et les paysages. A cette fin, des notions liées à la répétition et à la fragmentation des référents et des récits que le projet a impliqués, ont été utiles pour collecter et réarranger les indications suggérées par Rengifo.
\end{abstract}

\section{Le génie secret de la longue-vue (Kikkertens Hemmelighedsfulde Aand)}

\section{Mots clés}

Paysage, fragmentation, répétition, Kierkegaard. 


\section{Resumo}

Este texto é construído sobre diversas abordagens conceituais e teóricas para o projeto 0 gênio secreto da luneta (Kikkertens Hemmelighedsfulde Aand) da artista Sandra Rengifo. A perspectiva de análise colocada em funcionamento afasta-se dos discursos típicos da história da arte e da estética, e, ao contrário, ele instala questões mais próximas de campos de conhecimento como geografia cultural, estudos de paisagem e estudos visuais. 0 objetivo principal é descrever as relações e tensões que o projeto artístico mantém em relação a espacialidades, objetos, lugares e paisagens. Para tanto, noções relacionadas à repetição e fragmentação dos referentes e das narrativas que o projeto envolveu, foram úteis para coletar e rearranjar as indicações sugeridas por Rengifo.

\section{Palavras chaves}

Paisagem, fragmentação, repetição, Kierkegaard.

\section{Upacalla iuiai sug Catalejo (Kikkertens Hemmelighedsfulde Aand)}

\section{Maillallachiska}

Kai Kilkaska kame masnespa kauangapa tukuikuna, kuaura ruraskakuna catalejo (Kikkertens Hemmelighedsfulde Aand), ruradurmanda Sandra Rengifo, ruraska rurupe neskakuna, papa niskakuna, chinemanda, kai tapuchi kame ima iuiaska, kai iuiai kame ima iuiska, kai iuiai rigseska geografia culturamanda, chi referente riraska kauchi ima ruraska,ikute kauangapa y kauachingapa pai Rengifo.

\section{Rimangapa Ministidukuna}

Suma kauai, pitepite, ikute nesngapa, Kierkegaard. 
A finales de 2016, en Bogotá, la exposición Los lirios del campo y las aves del cielo (Lilien paa Marken og Fuglen under Himlen) me condujo al trabajo más reciente de Sandra Rengifo. Ese proyecto fue el resultado de una residencia de un año que Sandra había realizado en Flora ars+natura en esta misma ciudad. La exhibición confirmaba su fijación por Dinamarca sesgada por los escritos del filósofo existencialista cristiano Søren Kierkegaard, autor del libro que compartía el título con su muestra y guiaba su travesía danesa.

La experiencia en la exposición Los lirios del campo y las aves del cielo (Lilien paa Marken og Fuglen under Himlen) resultó sobrecogedora. La entendí no como una unidad de pretendida fidelidad de la narración audiovisual y la escenificación de pinturas y objetos con el texto de Kierkegaard, sino como un nudo de superposiciones sucesivas de paisajes que me llevaron como espectador de Gilleleje — sin conocer ese pueblo- a los Llanos Orientales colombianos y de ahí a una altiplanicie andina más familiar. La piedra de toque era la potencia con que la narrativa audiovisual afectaba mediante sentimientos de desposesión y abandono como los que, imagino, llegaron a experimentar artistas de otro tiempo y de otras tierras ante el paisaje natural, en particular al sentirse anulados frente a la exuberancia de la naturaleza y al intuir su lugar en la escala de lo vivo.

\section{**}

En la exposición El genio secreto del catalejo (Kikkertens Hemmelighedsfulde Aand) presentada en el Museo de Arte Moderno de Medellín entre marzo y junio de 2018, la indagación de Sandra Rengifo estrecha sus lazos con Kierkegaard a la vez que ahonda en la percepción de su entorno: mantiene distancia respecto a elementos culturales específicos, pone en tensión permanente lugares u objetos y distingue espacialidades, experiencias y tiempos. Todo esto, tal vez, a la manera de un ejercicio de lo que el geógrafo Yi-Fu Tuan denominó topofilia o interpretación inacabada de percepciones individuales en un marco de actitudes y valores colectivos en entornos específicos ${ }^{1}$.

Del nutrido repertorio de operaciones visuales y museográficas que la artista puso en trabajo en esta exposición, resultaron imágenes inquietantes y exigentes con su audiencia. Sin embargo, y aunque pudiera pensarse

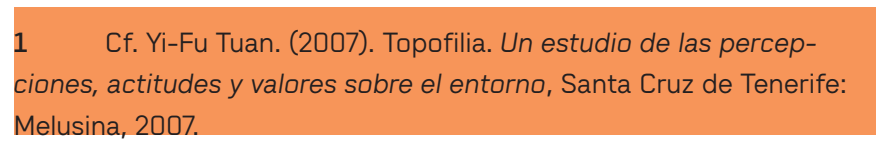

lo contrario, esta complejidad no está asociada a una armazón intelectual infundada, pues surgió más con el peso propio del cúmulo de indicios visuales que integran las narrativas y soportes apostados en El genio secreto del catalejo (Kikkertens Hemmelighedsfulde Aand), que aparecen insinuados en un pasaje de una de las cartas que Kierkegaard escribe a Regina Olsen, la cual es el referente central de este proyecto:

“Por tanto, a la mitad de una charla sobre la vista de los barcos, uno ve, o piensa que uno ve, o espera ver, o desea ver o desespera por ver lo que el genio secreto del catalejo tiene preparado, a quien entienda cómo usarlo correctamente. Únicamente, en las manos apropiadas y por medio del ojo adecuado, ese se convierte en un divino telégrafo, para todos los demás, es un artefacto inútil".

Søren Kierkegaard, Cartas, nro.17

***

El montaje fue compuesto por fragmentos —objetos, pinturas, serigrafías, fotografías, textos escritos, sonido y proyecciones múltiples y simultáneas de video-, es decir, es una imagen entretejida con muchas otras imágenes que cruzaron tiempos, espacios y artefactos. Por su parte la repetición de hitos que marca distintos paisajes, señala derivas que se superponen una y otra vez atravesadas por sugerencias provenientes de las ideas del filósofo danés. Al respecto, de nuevo la geografía subraya que los paisajes por definición están siempre en proceso, que son potencialmente conflictivos, incómodos, desordenados, erráticos, inacabados y abiertos. Al respecto, Joan Nogué afirma en la introducción del libro El paisaje en la cultura contemporánea que "para la cultura burguesa europea del siglo XIX los lagos nórdicos desprendían ternura, permanencia o pureza, para la misma cultura del siglo XX representan tranquilidad, equilibrio ecológico o contaminación"2.

En la dirección que propone Nogué, los lugares concretos en los que ocurrieron las décadas ominosas de la historia reciente del país muestran hoy cosas diferentes de las que antes eran posibles de ver, las cuales, además, animan aún hoy numerosas interpretaciones. En este punto, basta plantear algunas preguntas que recogieron la incomodidad e incompletud de las representaciones actuales de paisajes como los que Rengifo registró a lo largo de la cuenca de la Depresión

2 Cf. Joan Nogué. (2008). El paisaje en la cultura contemporánea, Madrid: Biblioteca Nueva, p. 11 
Momposina, los departamentos de Arauca, Valle del Cauca, Casanare, Córdoba, Bolívar y Cundinamarca: ¿qué pasa con otros paisajes que de repente aparecieron para muchos por cuenta del desescalamiento del conflicto en Colombia?, ¿cómo fue posible tolerar durante tanto tiempo las imágenes de estos espacios, sin habitantes humanos, a manera de magia salvaje para el ocio contemplativo desde los centros urbanos?, y finalmente: ¿de qué manera han cambiado la representación de esos espacios y los hitos que los georreferencian?

\section{****}

A propósito de las operaciones artísticas implicadas en El genio secreto del catalejo (Kikkertens Hemmelighedsfulde Aand), resulta útil detenerse en la idea de la fragmentación, la cual es una operación si se quiere "clásica" en el arte del siglo XX que se extendió sobre el mundo. Es importante que la noción de fragmento no sea reducida a un trozo de algo más, a un pedazo menos significativo de una unidad de sentido. Resulta más productivo si el fragmento es entendido como la condición impuesta por la contemporaneidad a lo que somos, hacemos y pensamos, es decir, a una constelación de acontecimientos que escapan de cualquier intento por homogeneizar la historia o por ordenar la vida propia. En este sentido, el proyecto de Rengifo configuró un territorio que no apareció nunca con claridad, apenas fue susurrado y no terminó de localizarse. Es más, tampoco opuso los estatutos de verdad que sugieren cada una de las capturas fotográficas, videográficas y pictóricas de paisajes y objetos, ni entre sus escalas y temporalidades que atestiguan lo que "debe ser callado".

La superposición y fragmentación de distintas narrativas del paisaje las replicó la estructura museográfica de El genio secreto del catalejo. La exposición se sirvió de relaciones constitutivas entre artefactos museográficos, objetos artísticos y montaje escenográfico con el fin de articular un conjunto, en apariencia fragmentado y repetitivo, insistiendo en la búsqueda del secreto entrañado de la carta que Søren Kierkegaard escribió a Regina Olsen.

Las decisiones espaciales tomadas para su escenificación, así como la estructura descrita, explican la forma como Rengifo configuró el proyecto al disponer de varias etapas del desarrollo de la obra a lo largo de un lapso, amplio e irregular. En estas condiciones vinculó a distintos colaboradores como el compositor Rune Borup quien produjo la música original, el fotógrafo Kim Wendt, el escenógrafo René Frisch Rasmussen, el actor Søren Bang Jensen e igualmente, requirió del apoyo de distintas instituciones que en algún punto del proceso ofrecieron insumos técnicos, estancias de residencia $u$ otros recursos para su producción, como fue el caso de esta, la que fue la versión más acabada y compleja del trabajo presentada en el Museo de Arte Moderno de Medellín.

Fernando Escobar Neira

Curador 


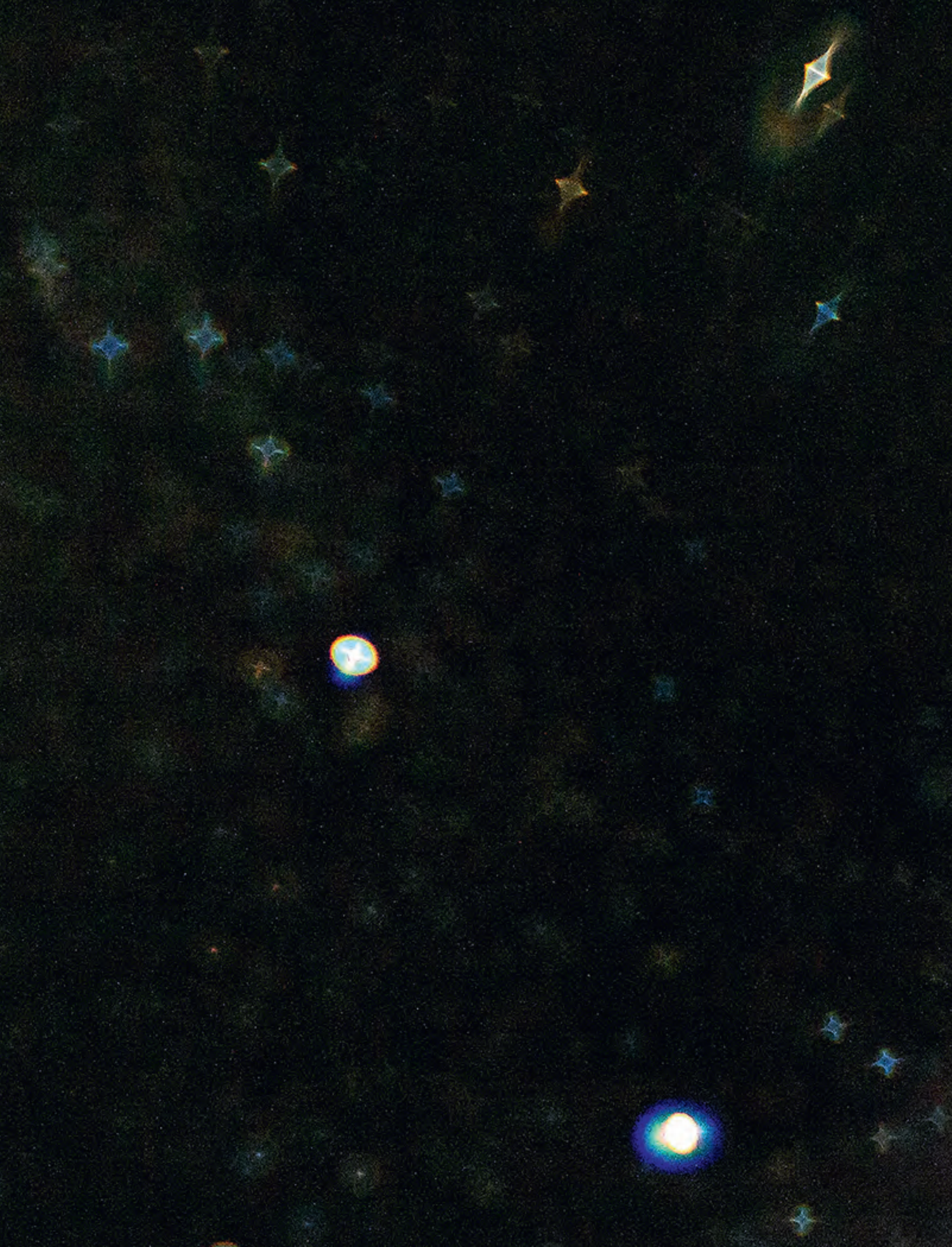




\section{seres}

Fotografía digital: Sandra Rengifo (2018). 4³5'56"N 7404'51"O. Impresión Chromaluxe. 
Fotografía digital: Sandra Rengifo (2018). 4³5'56"N 7404'51"O. Impresión Chromaluxe.

El genio secreto del catalejo (Kikkertens Hemmelighedsfulde Aand) // Sandra Rengifo, Fernado Escobar Neira // 263 


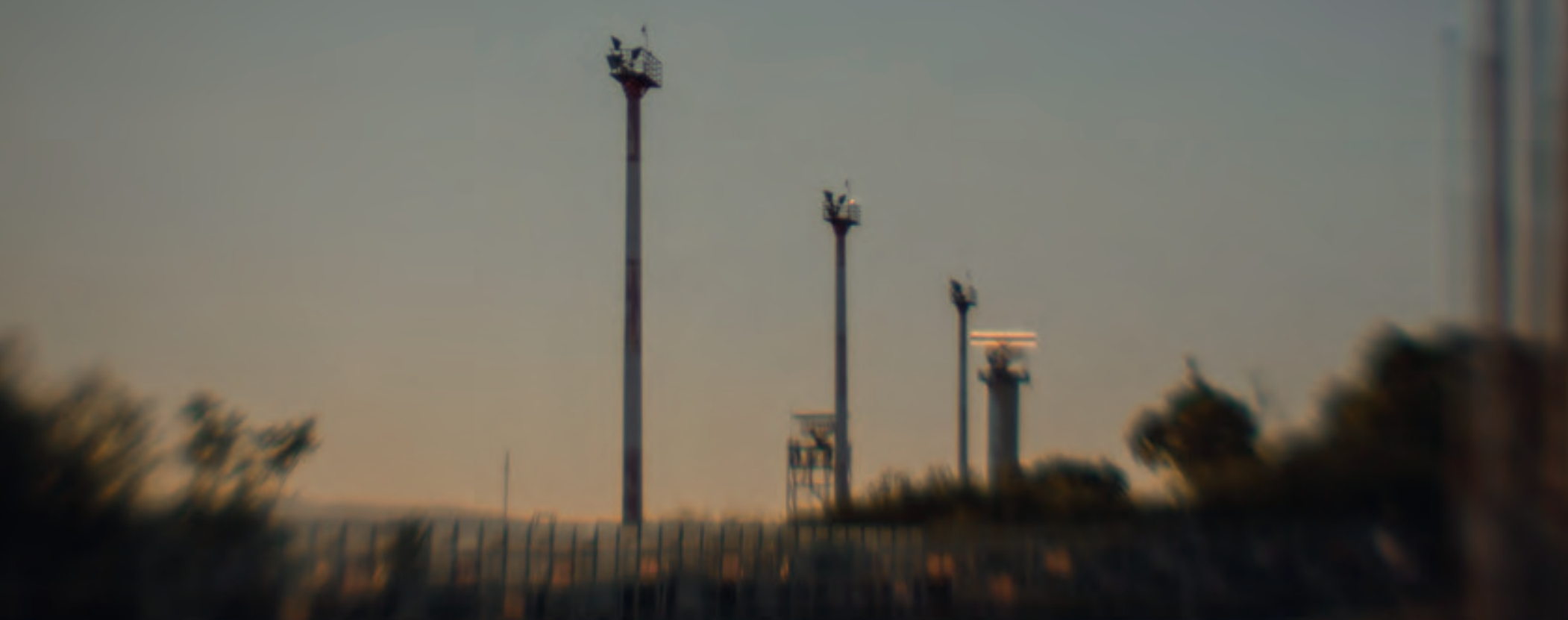

Fotografía digital: Sandra Rengifo (2017). 3753'54"N 2343'46"E. Impresión Chromaluxe. 


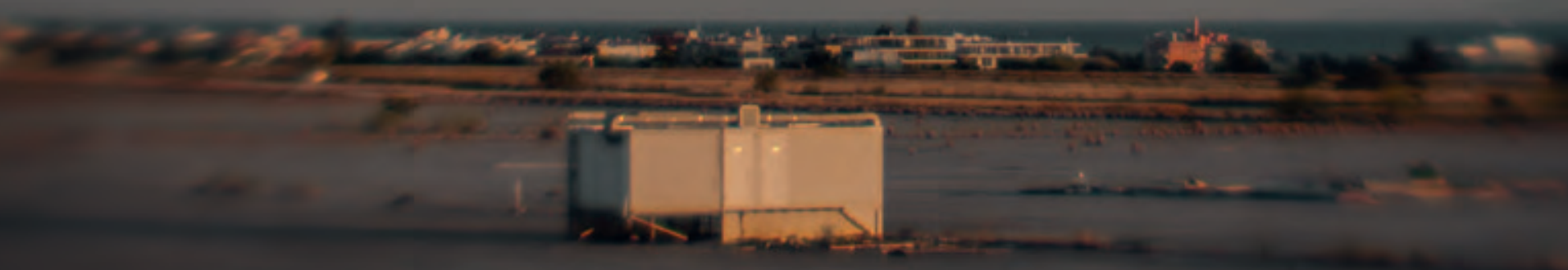

Fotografía digital: Sandra Rengifo (2017). 3753'54"N 2343'46"E. Impresión Chromaluxe.

\begin{abstract}
“iDesencadenaos en tempestad, salvajes elementos! Aun así, las olas lanzan la espuma hasta las nubes, no vais a poder alcanzarme: estoy tranquilo, como un rey de los escollos. Sin embargo, en ocasiones resulta difícil encontrar tierra firme y, cual pájaro marino, busco el sitio por el que penetrar en el enfurecido mar de mi alma. Pese a todo, esta excitación es mi elemento vital y edifico sobre ella, lo mismo que el alción construye su nido en el mar...".
\end{abstract}

Søren Kierkegaard

El genio secreto del catalejo (Kikkertens Hemmelighedsfulde Aand) // Sandra Rengifo, Fernado Escobar Neira // 265 


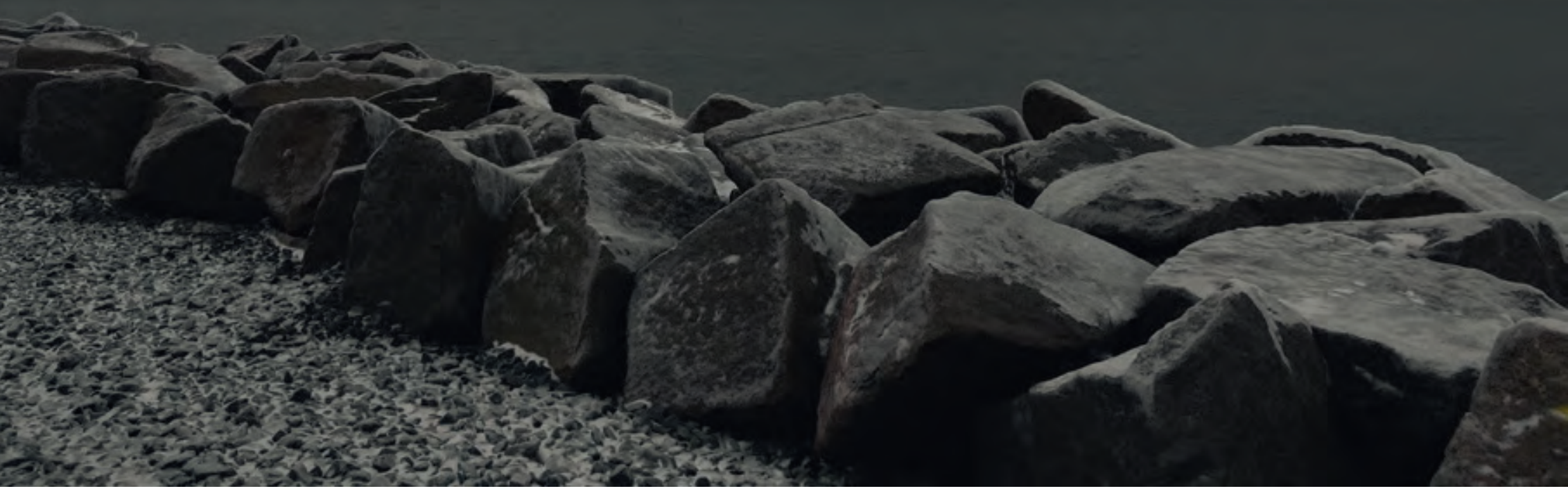

Fotografía digital: Sandra Rengifo (2017). 5540'34"N 12³4'08“E. Impresión Chromaluxe. 
Fotografía digital: Sandra Rengifo (2018). 4³5'56"N 7404'51"O. Impresión Chromaluxe.

268 // CALLE14 // volumen 13, número 24 // julio - diciembre de 2018 


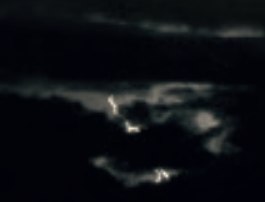

Fotografía digital: Sandra Rengifo (2018). 4³5'56"N 7404'51"O. Impresión Chromaluxe. 


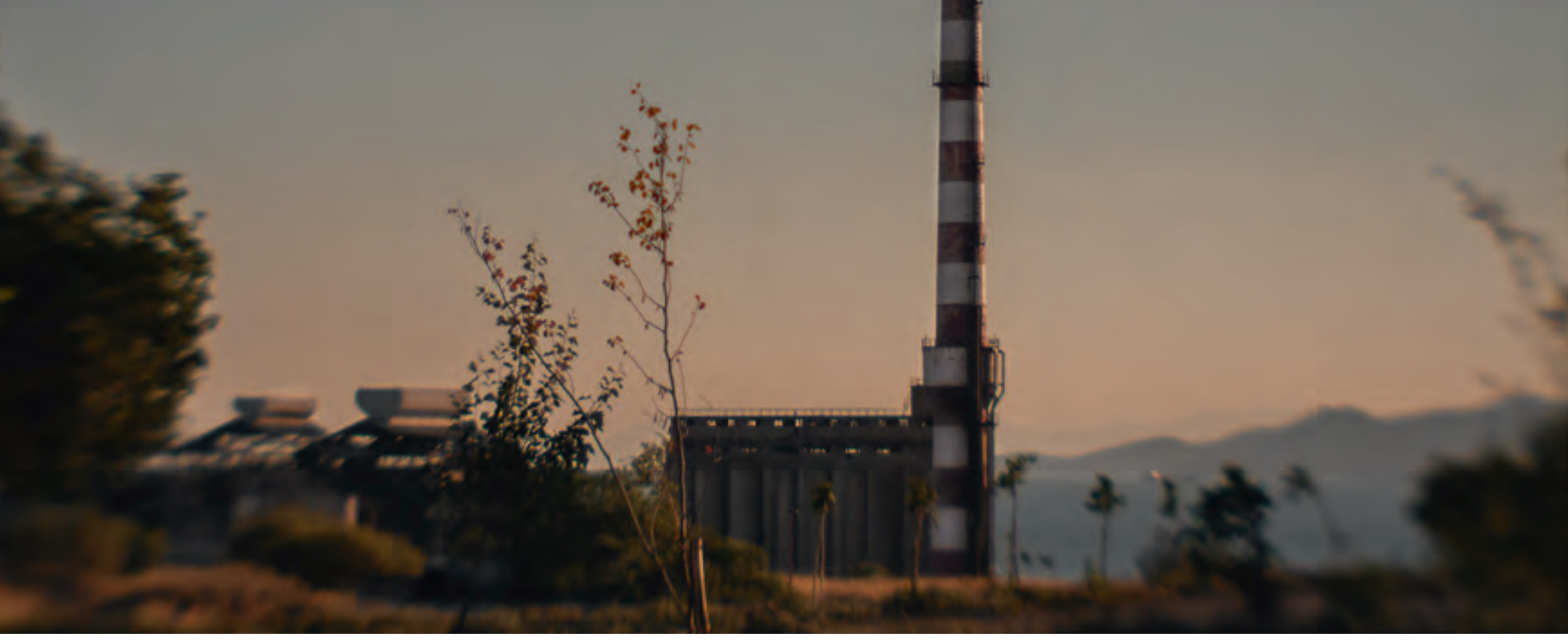

Fotografía digital: Sandra Rengifo (2017). Drapetsona. Impresión Chromaluxe. 
Fotografía digital: Sandra Rengifo (2017). 35¹8'35"N 2453'36"E. Impresión Chromaluxe. 


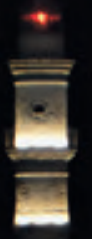

El genio secreto del catalejo (Kikkertens Hemmelighedsfulde Aand) // Sandra Rengifo, Fernado Escobar Neira // 273 


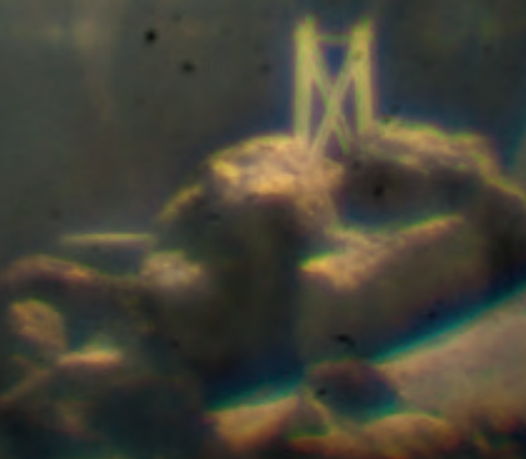

Fotografía digital: Sandra Rengifo (2 017). 35¹8'35"N 2453'36"E. Impresión Chromaluxe. 
Fotografía digital: Sandra Rengifo. (2018). Sendero del silencio. Impresión Chromaluxe. 

Fotografía digital: Sandra Rengifo. (2017). Stjernesti. Impresión Chromaluxe. 
“Mi Regina!

Éste es el puente Knippel. Yo soy esa persona con el catalejo. Como tú sabes, las figuras que aparecen en el paisaje son aptas para parecer algo curiosas. Así que puedes reconfortarte de que yo no aparezca tan feo y que cada concepción artística siempre conserva algo del ideal, incluso en caricatura.

Muchos expertos en arte han estado en desacuerdo en por qué el pintor no proporcionó ningún fondo. Algunos han pensado que ésta es una alusión a aquél cuento popular sobre un hombre quién se perdió completamente en el disfrute de la vista del puente Knippel que al final él no vio nada más que la pintura producida por su propia alma y por la que él podría bien haber estado viendo un cuarto obscuro. Otros han pensado que era porque carecía de la perspectiva necesaria para dibujar —casas.

Pero el catalejo en sí mismo tiene una característica sobre la cual, la tradición nos dice lo siguiente: el lente exterior es de vidrio de espejo para que cuando uno lo disponga en Trekroner [Tres coronas] y se pare al lado izquierdo del puente, en un ángulo de 35 grados fuera de Copenhague, uno vea algo completamente diferente sobre sí, de todo lo que se ha visto por toda la demás gente. Por tanto, a la mitad de una charla sobre la vista de los barcos, uno ve, o piensa que uno ve, o espera ver, o desea ver o desespera por ver lo que el genio secreto del catalejo tiene preparado, a quien entienda cómo usarlo correctamente. Únicamente, en las manos apropiadas y por medio del ojo adecuado, ése se convierte en un divino telégrafo, para todos los demás, es un artefacto inútil"

SK, Cartas, no.17 


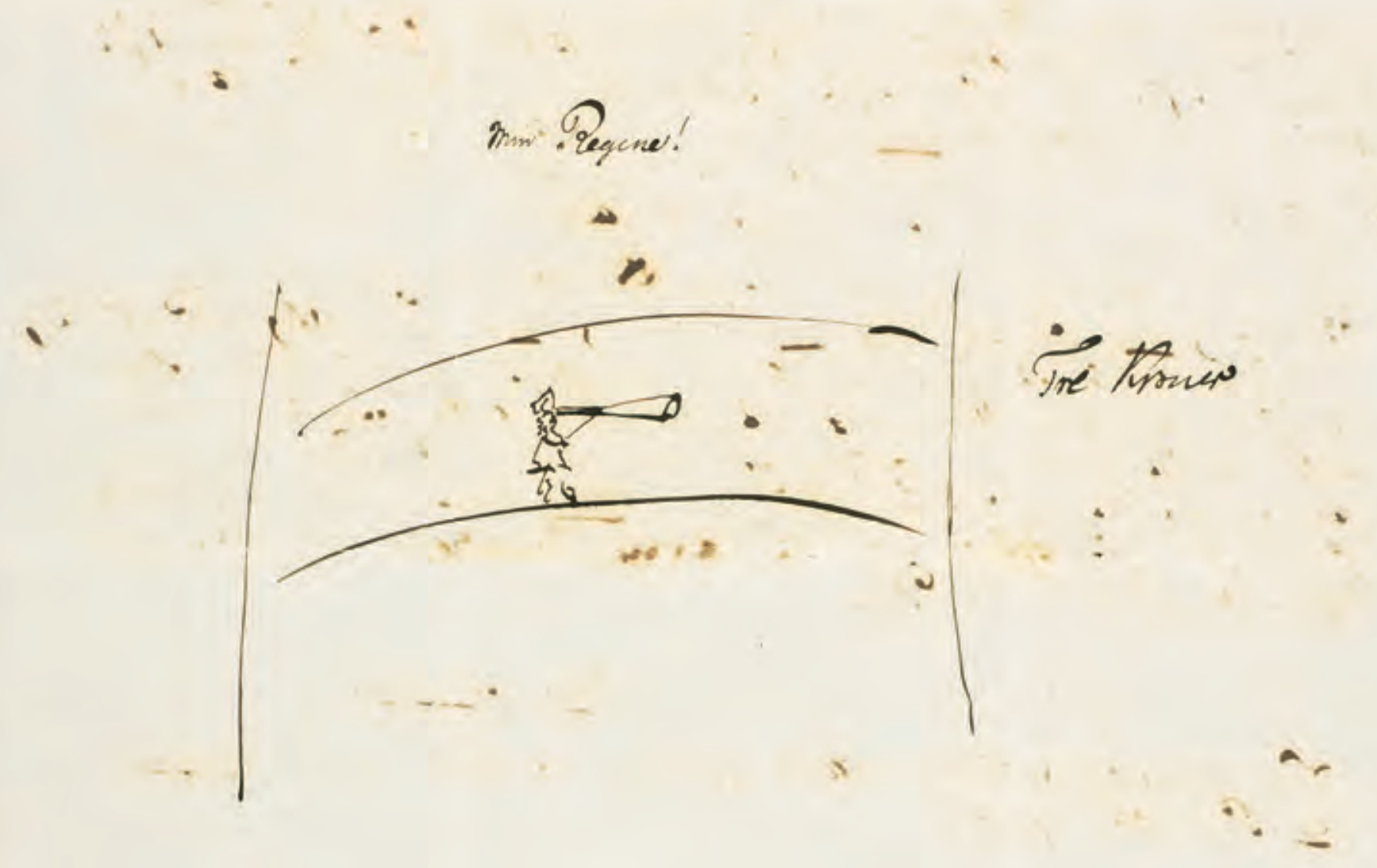

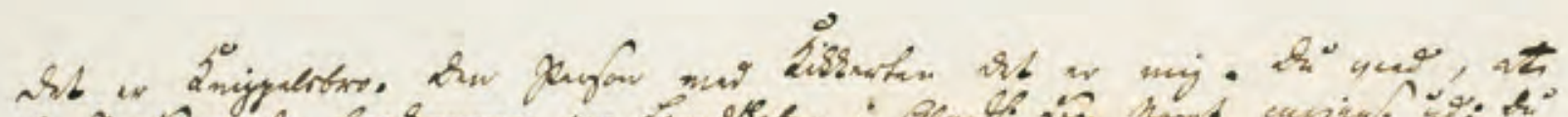

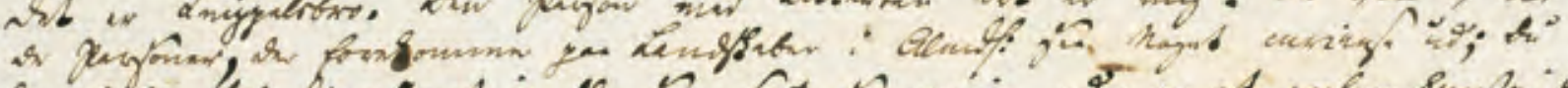

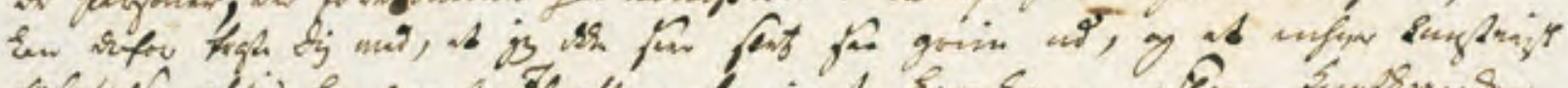

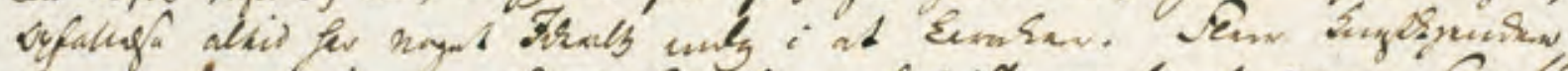

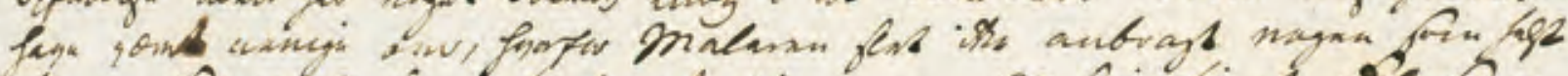

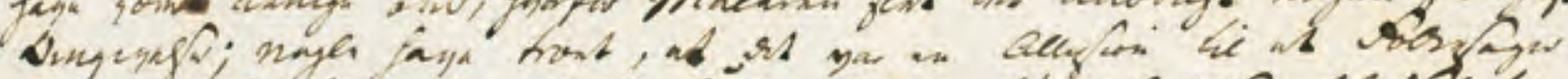

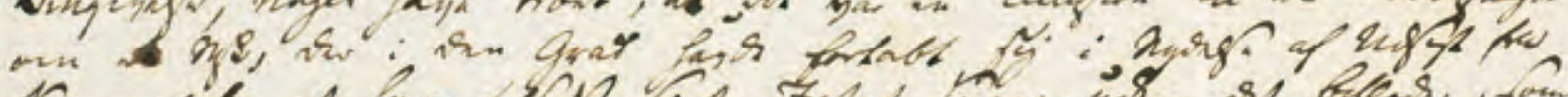

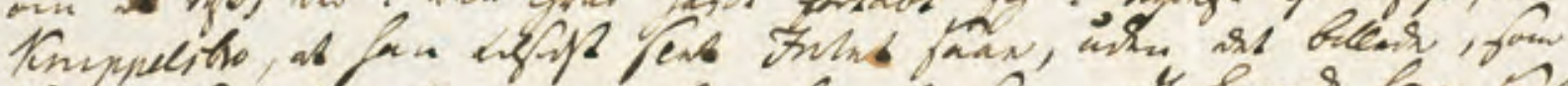

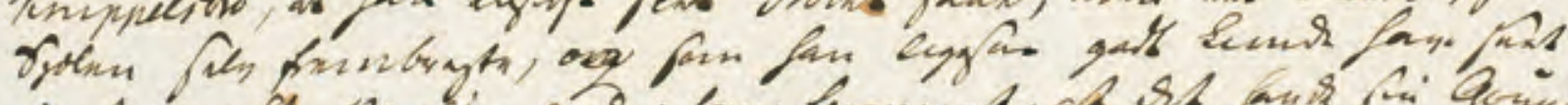

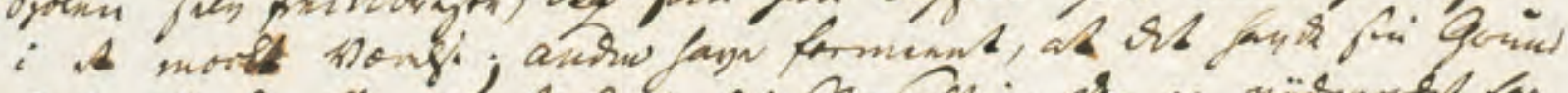

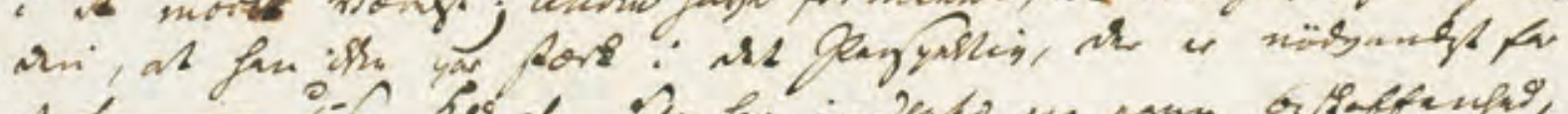

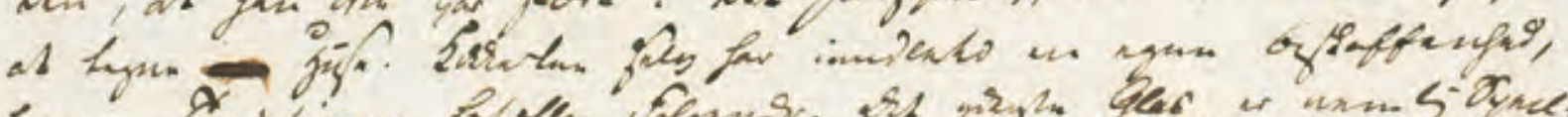

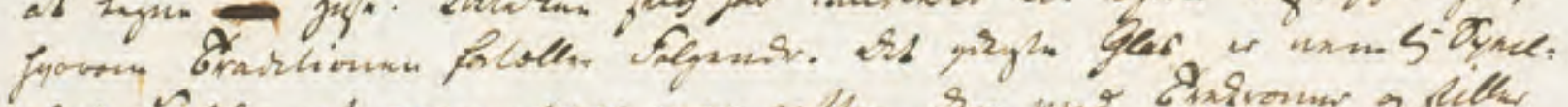

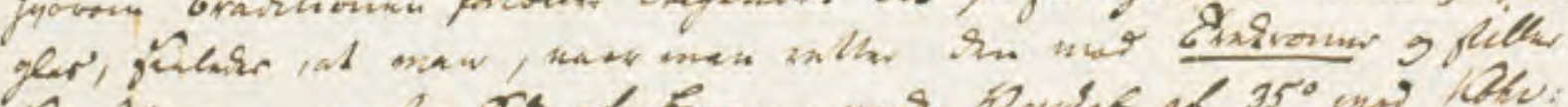

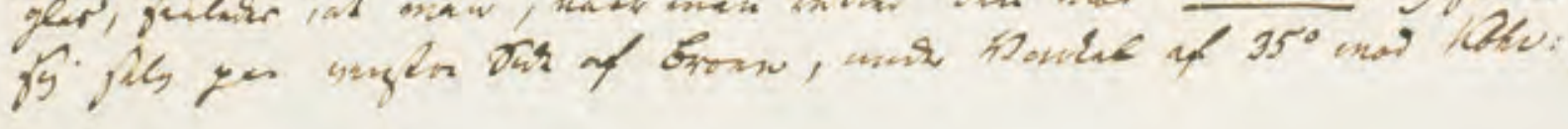




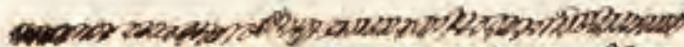
Q70p

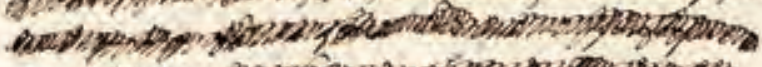

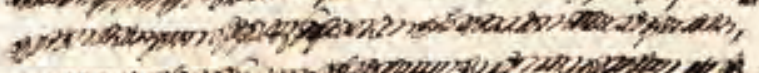

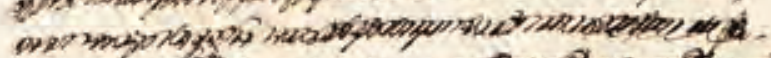

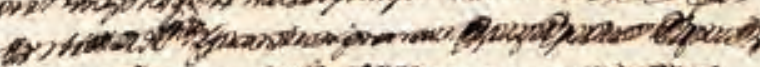

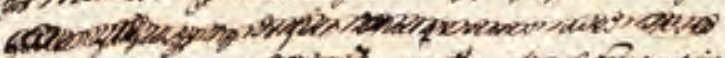

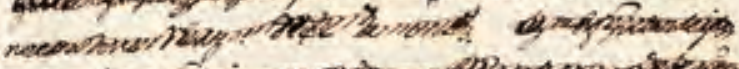

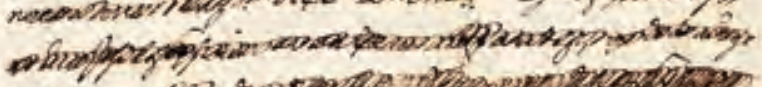

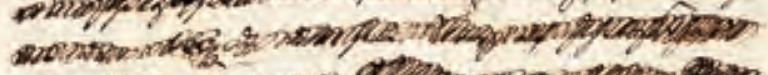

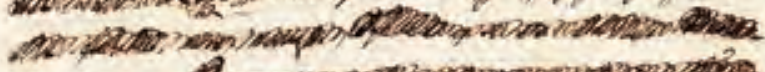

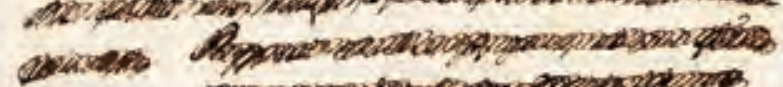

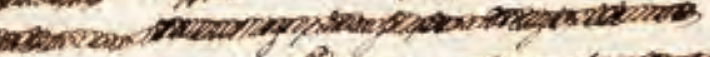

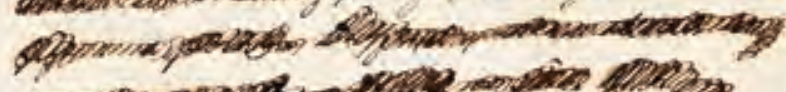

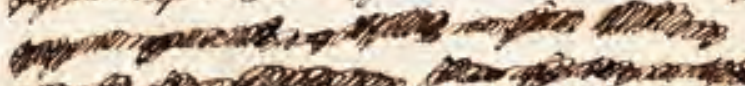

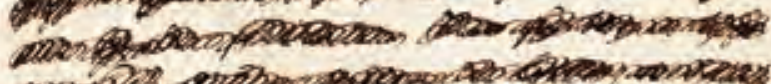

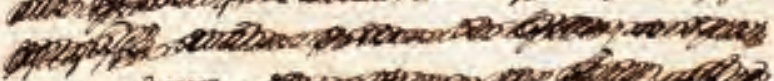

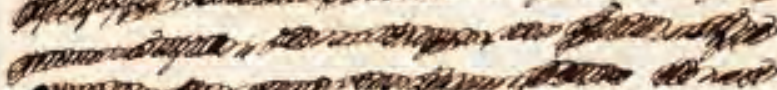

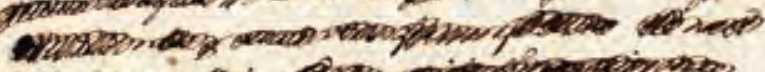

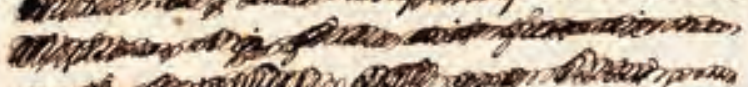

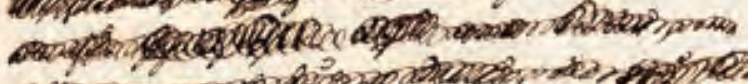
ar

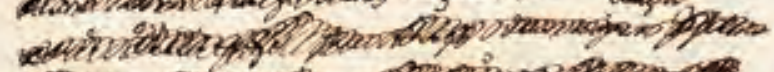

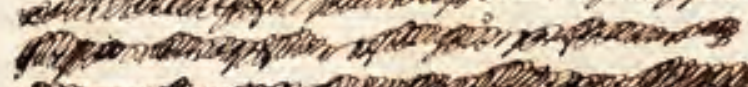

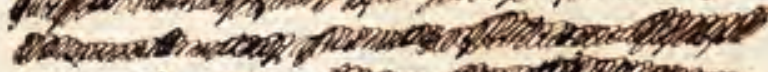

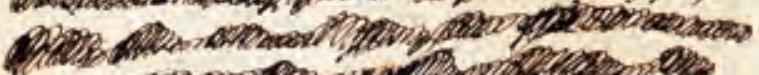

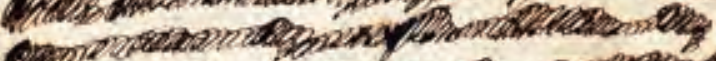

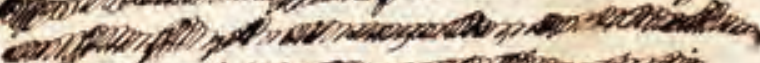

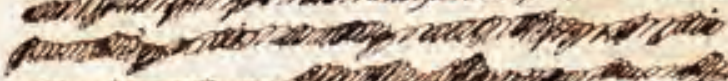

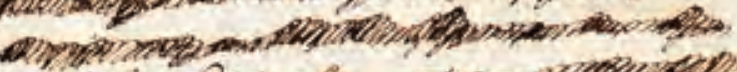

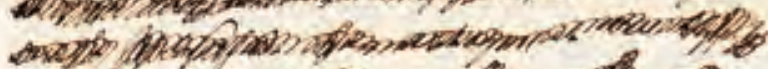

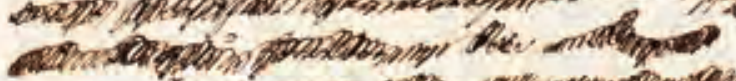

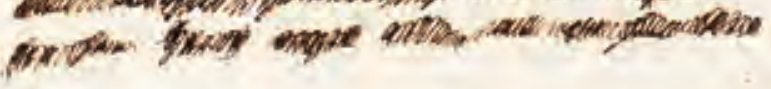

Borrador de "Diapsalmata" (Copia intervenida digitalmente e impresa en serigrafía por la artista del manuscrito original de Søren Kierkegaard que reposa en The Royal Danish Library, Den Sorte Diamant.)

En esta versión de manuscrito de otra parte de Enten-Eller (O lo Uno o lo Otro: La alternativa/ Diapsalmata), Kierkegaard ha borrado de manera sistemática extensas partes del texto con trazos de tinta. Solo las palabras introductorias han sobrevivido: "Prefiero hablar con niños, pues de ellos puede aún albergarse la esperanza de que se conviertan en seres racionales; pero con aquellos que ya se han convertido en tales... iVálgame Dios! ${ }^{1}$

1 Versión original de los textos traducidos de los manuscritos, disponible en: https://artsandculture. google.com/exhibit/søren-kierkegaard/QRf3bzQ1. Consultado junio 15 de 2017. 


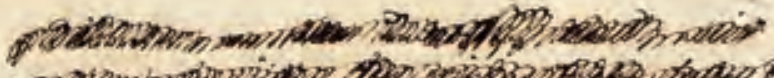

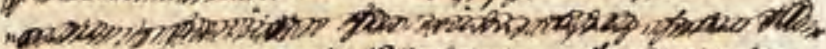

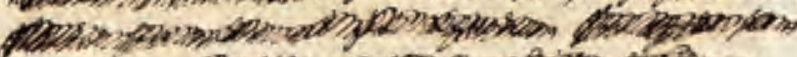

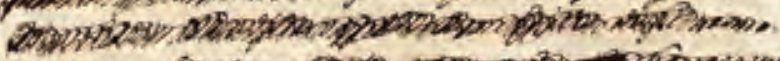

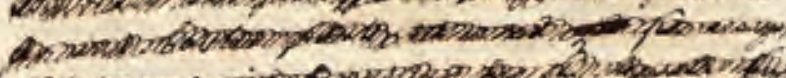
ow

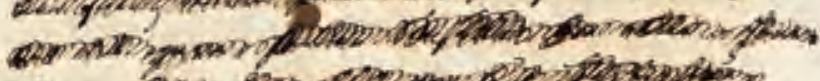

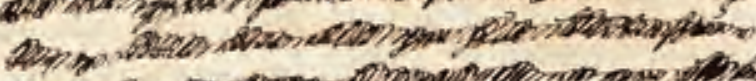

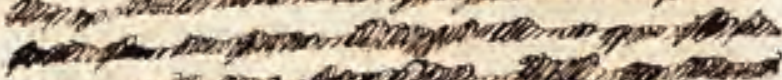

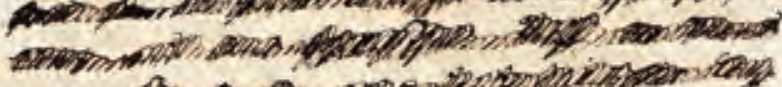

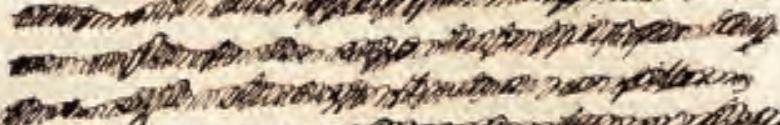

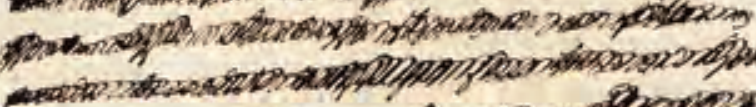

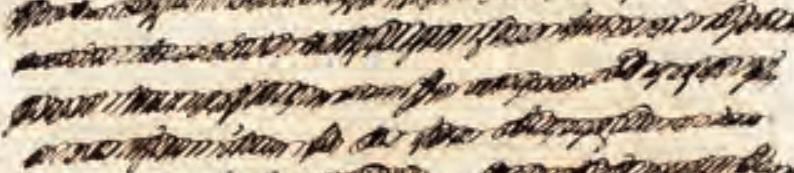

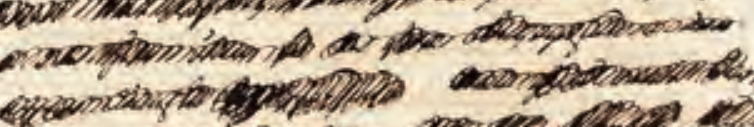

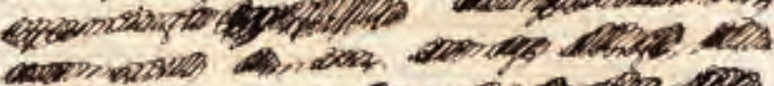

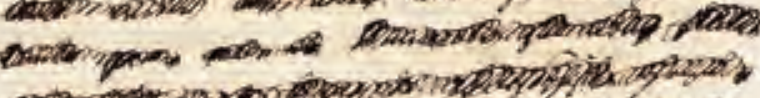

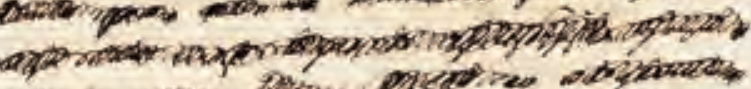

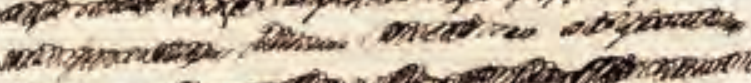

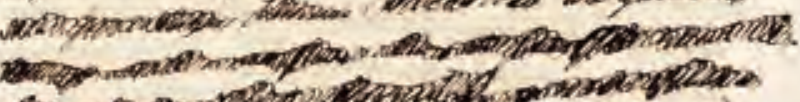

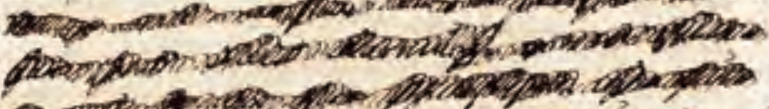

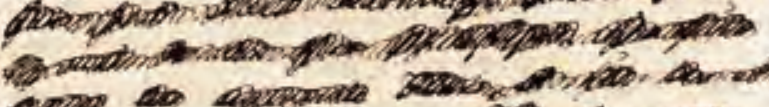

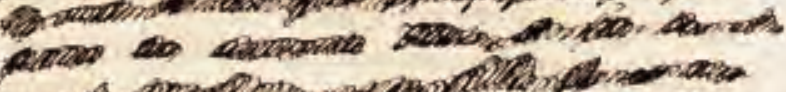
Q

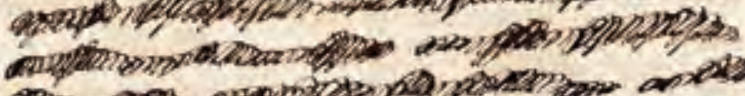

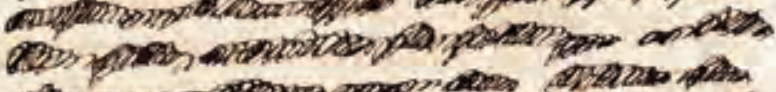

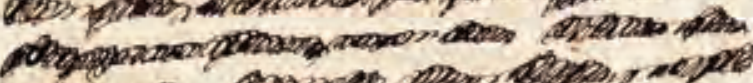

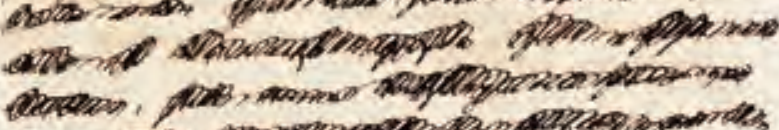

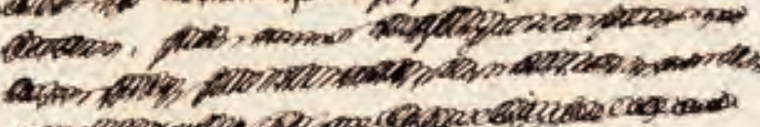

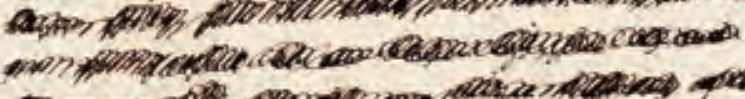

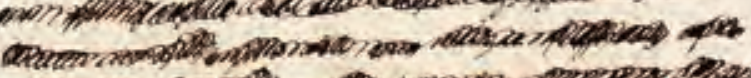

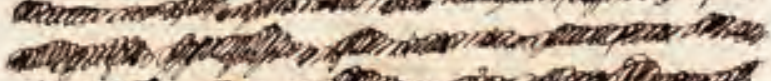

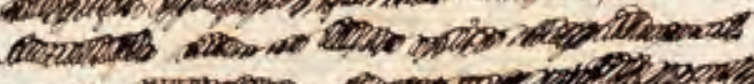

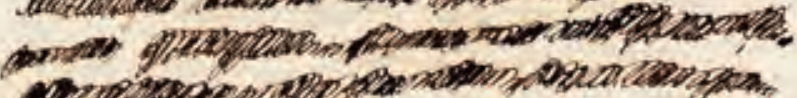

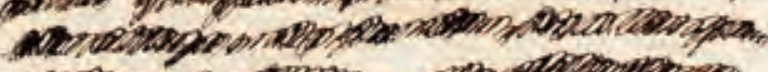

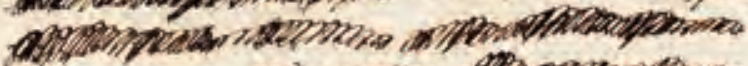
Q

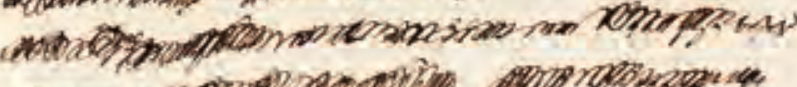

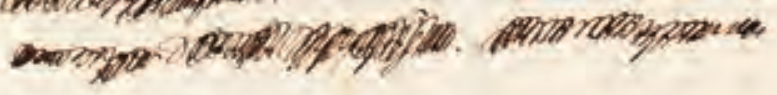




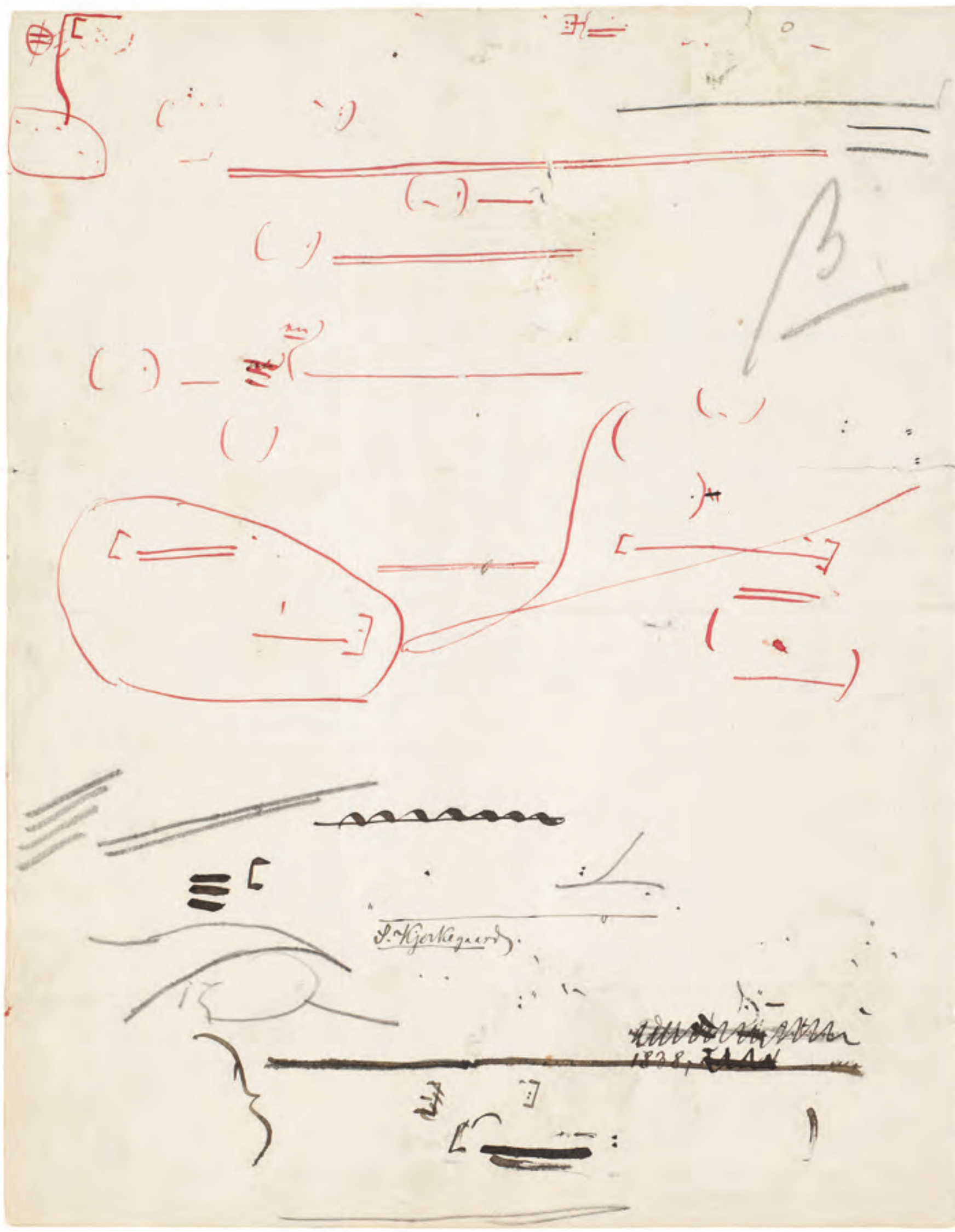

Manuscrito (Copia intervenida digitalmente e impresa en serigrafía por la artista del manuscrito original de Søren Kierkegaard que reposa en The Royal Danish Library, Den Sorte Diamant.)

Antes de que sus escritos adquirieran su forma final, Kierkegaard produjo varios "ejercicios de escritura," por ejemplo un drama titulado "La disputa entre la vieja y la nueva jabonería. Drama heróico-patriótico-cosmopolitafilantrópico-fatalista." Sin embargo, el manuscrito permaneció en el cajón, como se podría asumir, tal vez, dado el caos de esta página. 


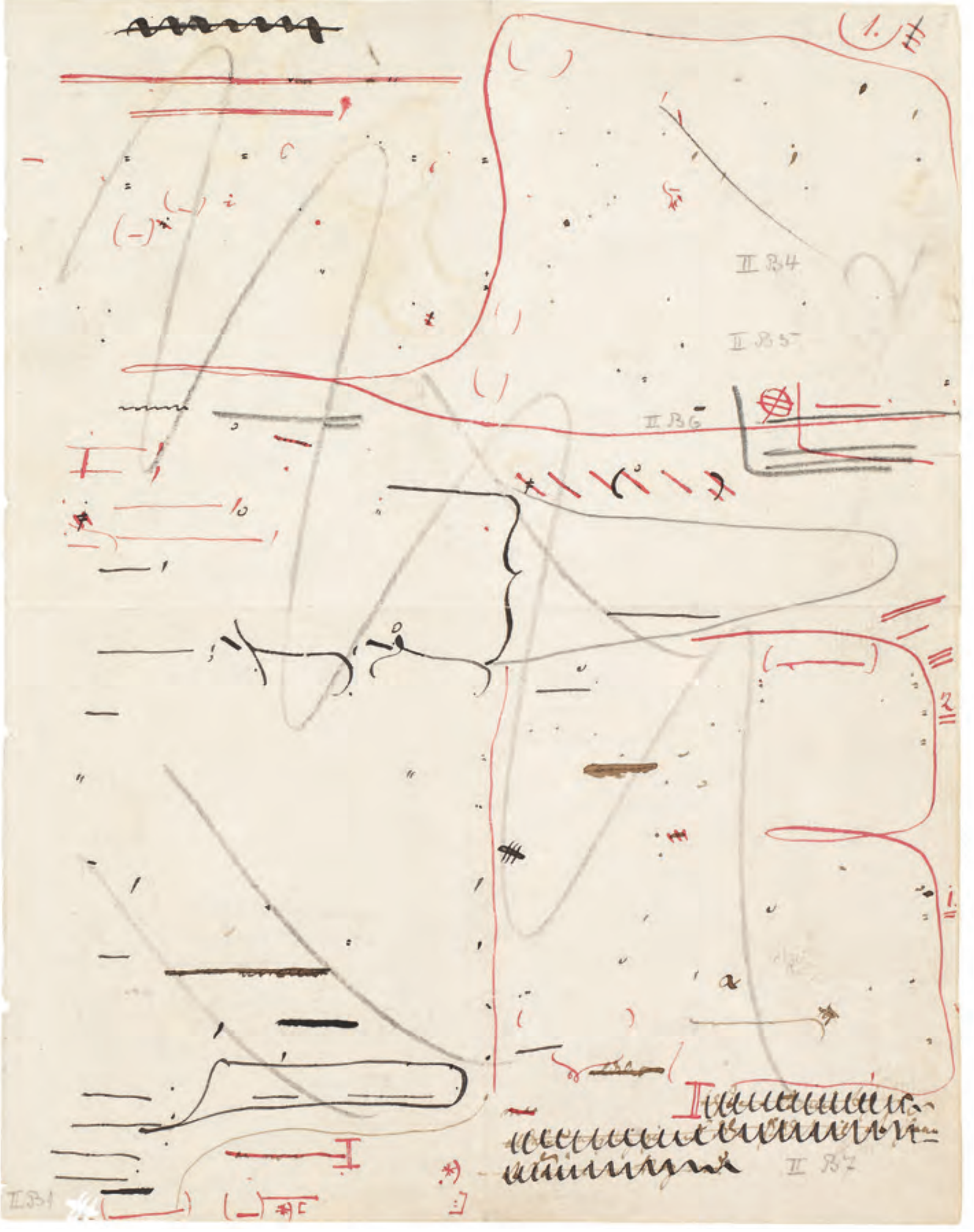




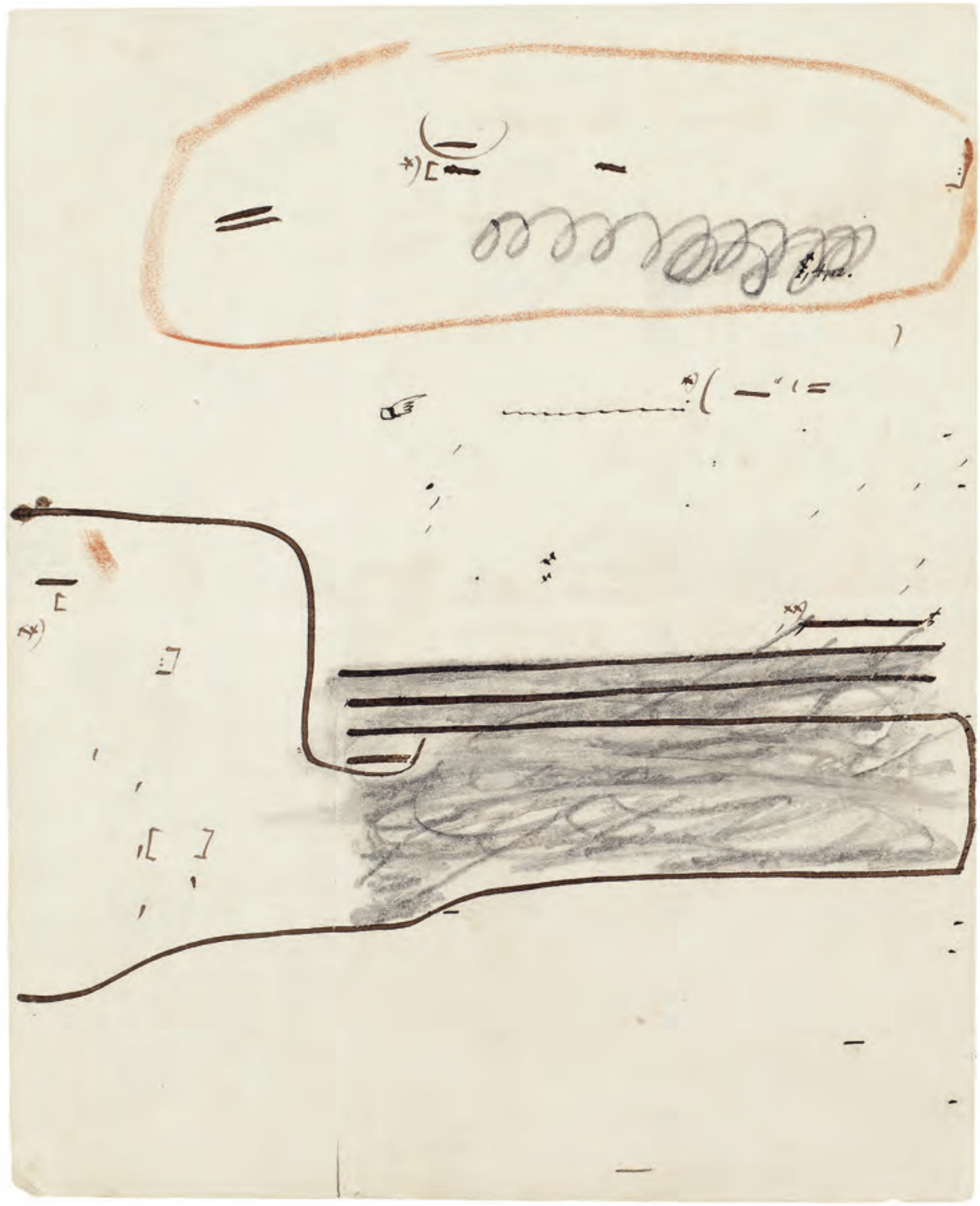

Manuscrito " De todo hay que dudar" (Copia intervenida digitalmente e impresa en serigrafía por la artista del manuscrito original de Søren Kierkegaard que reposa en The Royal Danish Library, Den Sorte Diamant.)

Otro texto incompleto es la novela autobiográfica de alrededor 1842-43 titulada Johannes Climacus or De omnibus dubitandum est ("De todo hay que dudar"). Puede que haya sido abandonada sin finalizar debido a que Kierkegaard no pudo conciliar el género de la novela con la doctrina filosófica. 


\section{sapming}

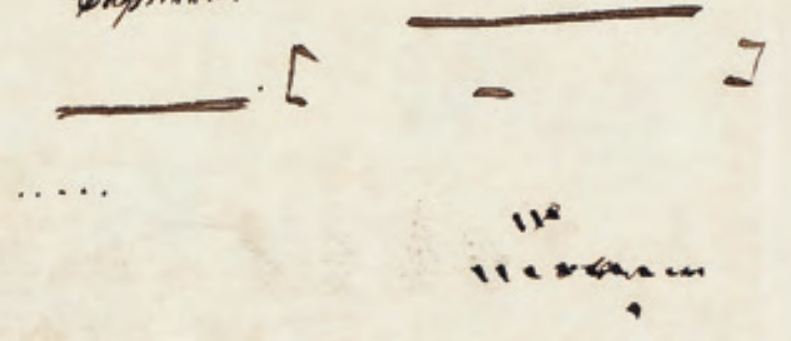

Lum thambins 


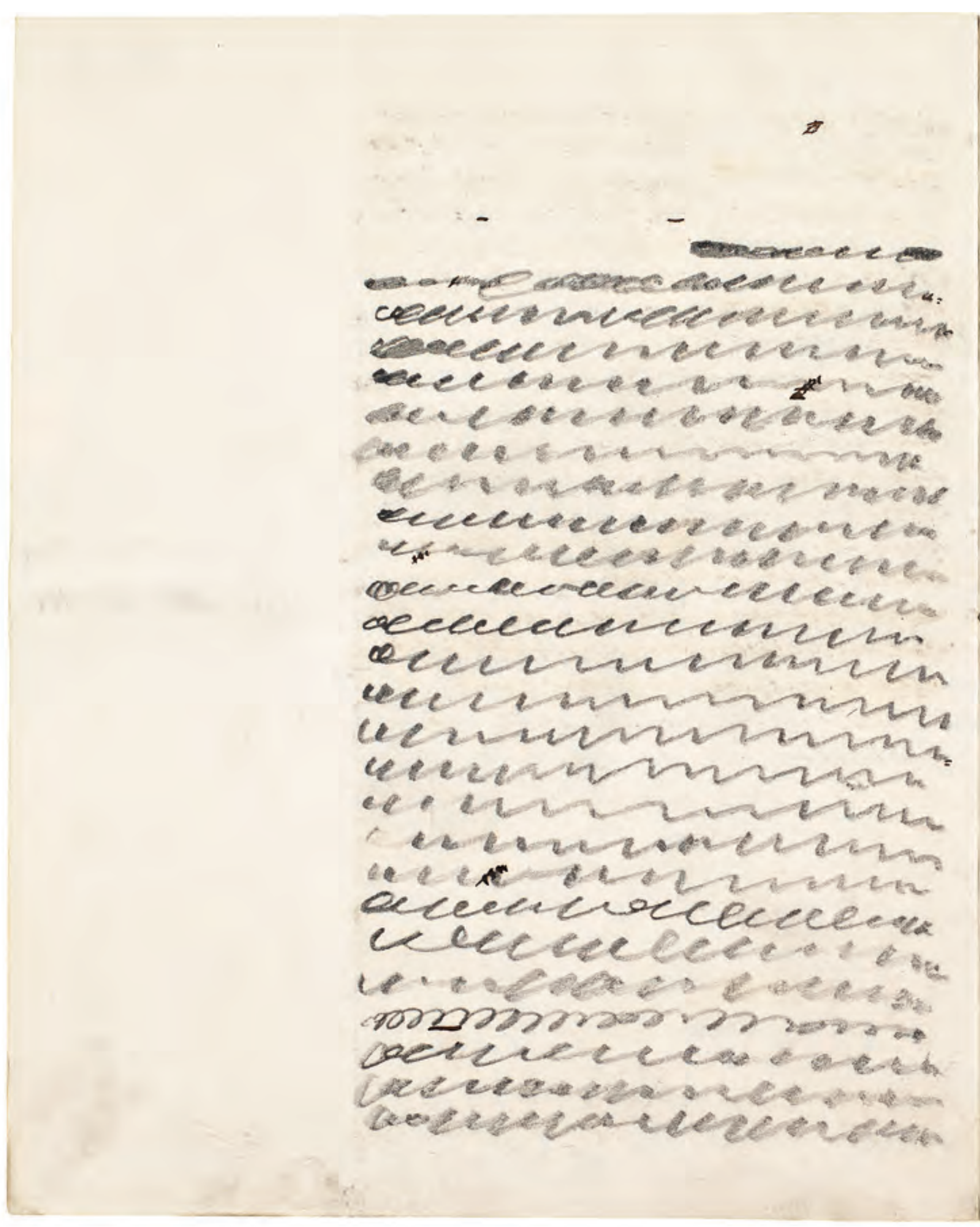

Copia virgen de "Cristo es el camino" (Copia intervenida digitalmente e impresa en serigrafía por la artista del manuscrito original de Søren Kierkegaard que reposa en The Royal Danish Library, Den Sorte Diamant.)

Copia virgen de "Cristo es el camino" de "Para un examen de sí mismo recomendado a este Tiempo." Una parte sustancial del texto ha sido borrada a lápiz y reemplazada con la adición al margen escrita en tinta en la página 106. 


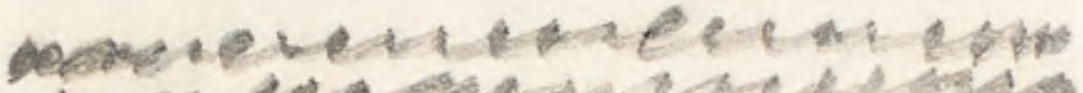

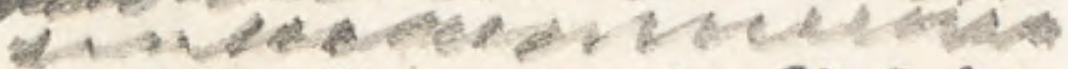

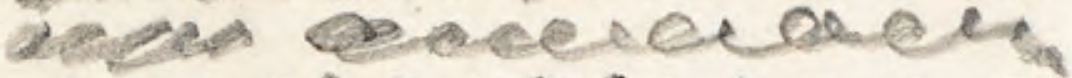

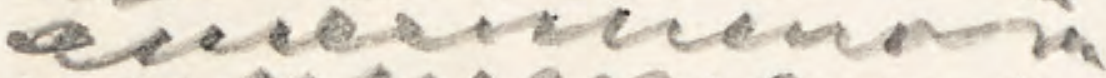

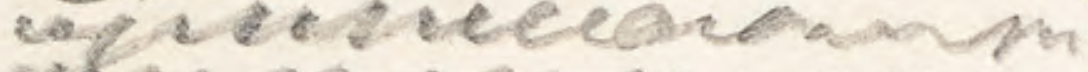

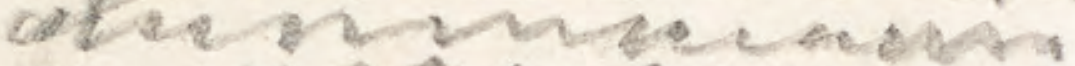

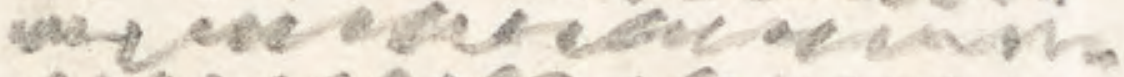
$\cos ^{4}$ e

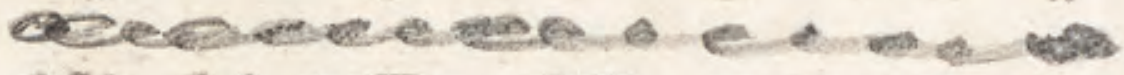

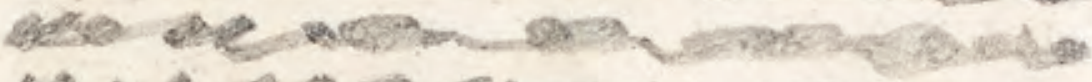

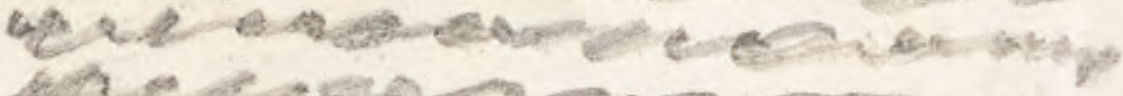

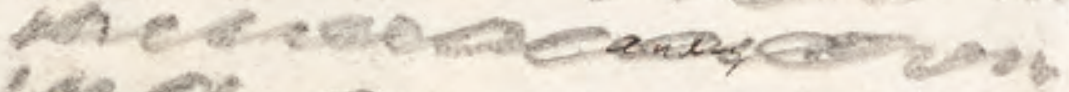

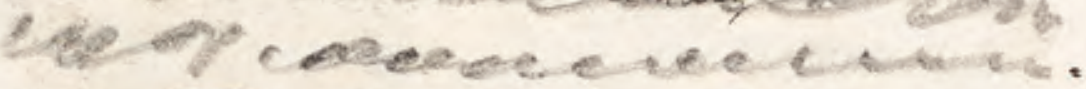
ef

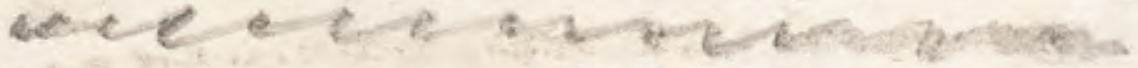

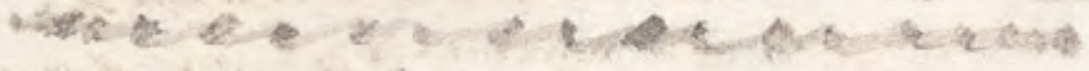

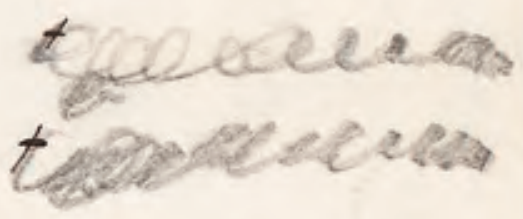

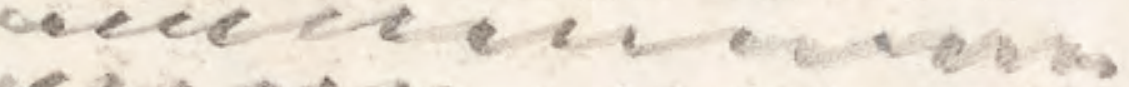

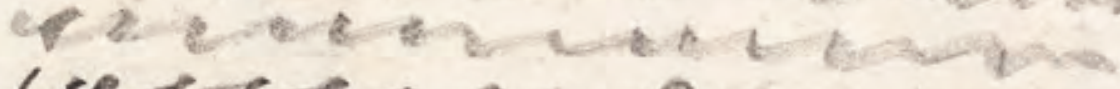

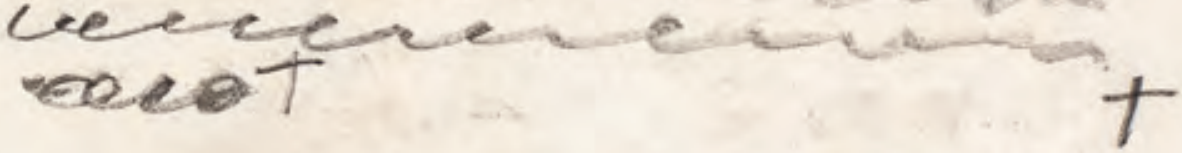

